\title{
Correction to: 3, 3'-Diindolylmethane-encapsulated chitosan nanoparticles accelerate molecular events during chemical carcinogen-induced mammary cancer in Sprague Dawley rats
}

\author{
Stainsloss Isabella ${ }^{1} \cdot$ Sankaran Mirunalini ${ }^{1}$
}

Published online: 30 September 2020

(C) The Japanese Breast Cancer Society 2020

\section{Correction to: Breast Cancer (2019) 26:499-509 https://doi.org/10.1007/s12282-019-00950-x}

In the original publication of the article, the Fig. 3 was published with errors. The correct Fig. 3 is given in this correction.

In addition, the first paragraph under the section heading "Immunohistochemical (IHC) expression of Cyclin D1 and PCNA in mammary tissues of control and experimental rats" should read as below:

The IHC expression of Cyclin D1 (A-F) and PCNA (G-L) in mammary tissues of control and experimental rats are represented in Fig. 3. The expression of Cyclin D1 and PCNA were found to be significantly increased in DMBAinduced tumor-bearing rats $(\mathrm{B}, \mathrm{H})$ when compared to control (A) rats. Whereas, the levels of Cyclin D1 and PCNA were found to be decreased during treatment with DIM@ CS-NP $0.5 \mathrm{mg} / \mathrm{kg}$ b.wt (D and J) compared to DIM $10 \mathrm{mg} /$ $\mathrm{kg}$ b.wt (C, I) significantly. However, the administration of DIM (E, K) and DIM@CS-NP (F, L) did not show any significant $(p<0.05)$ changes in the expression of Cyclin D1 and PCNA.

Publisher's Note Springer Nature remains neutral with regard to jurisdictional claims in published maps and institutional affiliations.

The original article can be found online at https://doi.org/10.1007/ s12282-019-00950-x.

Sankaran Mirunalini

mirunasankar@gmail.com

Stainsloss Isabella

isabelladtf@gmail.com

1 Department of Biochemistry and Biotechnology,

Annamalai University, Annamalai Nagar, Chidambaram,

Tamil Nadu 608 002, India 

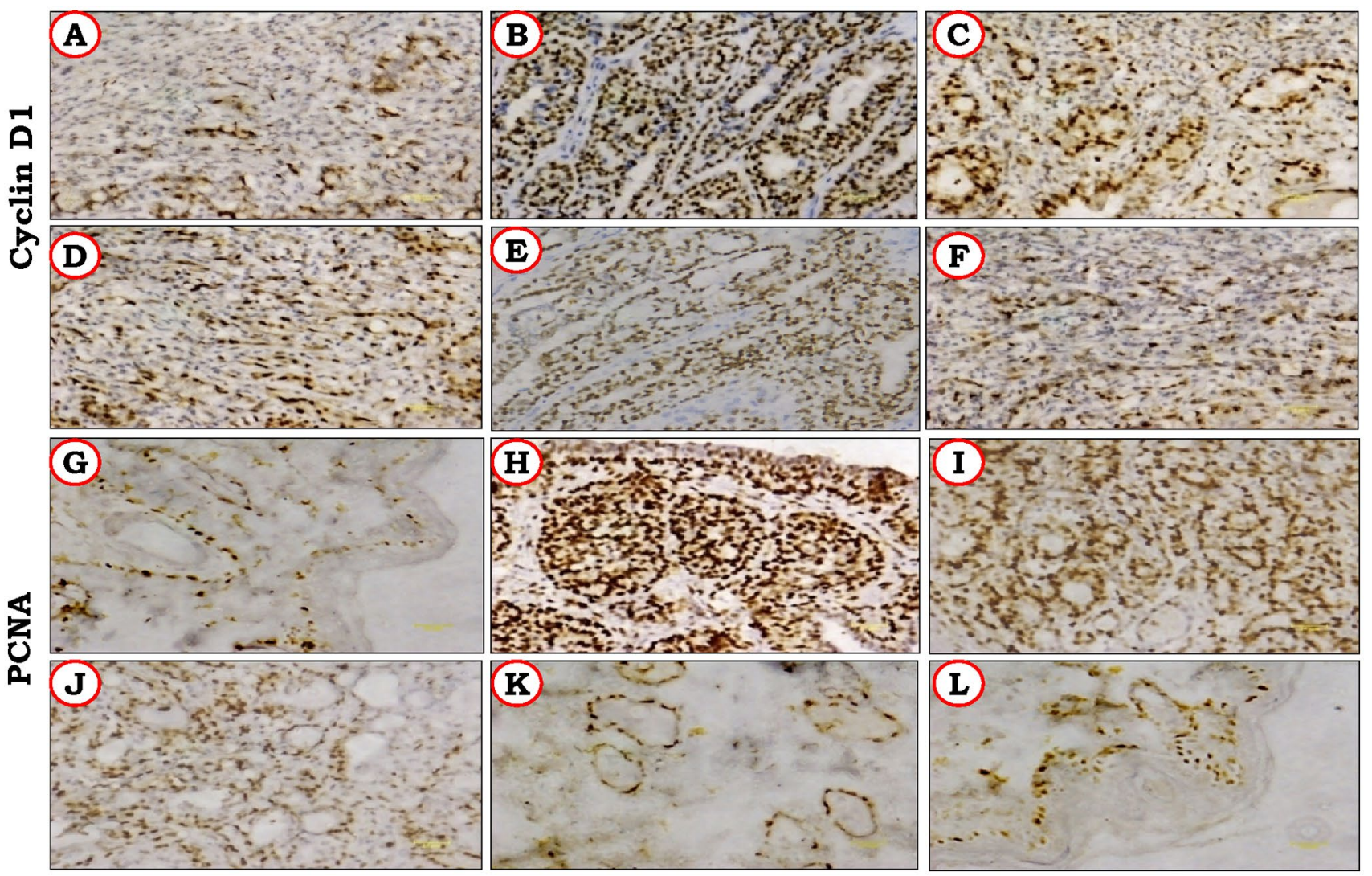

Fig. 3 Effect of DIM and DIM@CS-NP on the immunohistochemical analysis of Cyclin D1 (a-f) and PCNA (g-l), respectively, in mammary tissue of control and experimental rats. The control (a, g), DIM (e, k), and DIM@CS-NP (f, l) showed normal mammary tissue stain- ing, the DMBA-induced rats $(\mathbf{b}, \mathbf{h})$ showed increased expression of Cyclin D1 and PCNA when compared with control rats. However, oral administration of DIM@CS-NP $(\mathbf{d}, \mathbf{j})$-treated rats showed diminished expression levels as compared to DIM (c, i) administration 